\title{
CORRECTION OF MEASURED TRAFFIC VOLUME ON EXPRESSWAYS BASED ON TRAFFIC VOLUME BALANCING
}

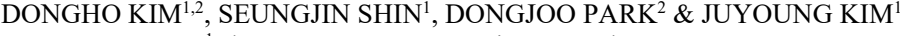 \\ ${ }^{1}$ The Korea Transport Institute, South Korea \\ ${ }^{2}$ Department of Transportation Engineering, University of Seoul, South Korea
}

\begin{abstract}
This study developed an optimization method to correct the measured expressway traffic volume that minimizes measurement errors and satisfies the traffic balancing with TCS. For this purpose, the model constructed in this study was compared with the true traffic volume and verified. Through the verification of the model, it was found that the measurement error is reduced when the measured traffic volume is corrected for the traffic volume balance. By applying it to 21 links of the Gyeongbu expressway, the measured traffic volume was corrected by $-8.1 \% \sim 9.6 \%$ and the measurement error was decreased as much as the corrected traffic volume. This research is meaningful in terms of improving the accuracy of the measured traffic volume of the expressway, which is significant considering that the role of the expressway are increasing.
\end{abstract}

Keywords: traffic volume correction, traffic volume balancing, TCS (toll collection system), optimization model.

\section{INTRODUCTION}

With the recent increase in the role of expressways, the traffic volume information of expressways has been used in many areas, including the operation and management of expressways, route planning, air pollution, and the calculation of carbon dioxide emissions. As the value of expressway traffic volume information increases, it is surveyed every year in Korea according to Article 102 of the Road Act to prepare the annual traffic volume report [1]. The traffic volume survey is divided into frequent surveys and regular surveys, which collect traffic volume by vehicle type, direction, and time period. Frequent surveys are conducted for one day on Thursday of the third week of October using VDS and CCTV, and regular surveys use AVC equipment to collect traffic volume for a year. However, the expressway traffic volume information collected is somewhat inaccurate due to the limitations of the collection technology and detector [2], [3]. Before using such expressway traffic volume, it is necessary to measure and correct the accuracy, because reliable results cannot be obtained through the use of inaccurate data. In order to correct the traffic volume, it is necessary to investigate the actual traffic volume of the main line and ramp, but this involves a lot of time and money.

Over the years, numerous studies have been performed with the aim of correcting the traffic volume information (hereinafter, measured traffic volume) collected from expressway detectors [4]. Most of the studies performed correction based on consistency with traffic flow theory and historical data, but did not consider traffic balancing on the basis of network consistency [5]-[8]. In other words, the traffic volume entering and exiting the road does not satisfy the traffic volume conservation law, which must be consistent with the traffic volume remaining in the corresponding section. Considering these limits, in some studies the measured traffic volume from the detector is assumed to be the actual traffic volume, and the measured traffic volume is corrected to satisfy the requirement of traffic volume balance within a certain [9]-[12]. However, since the measured traffic volume collected from the 
detector includes errors, the corrected measured traffic volume may cause larger errors when the traffic volume is corrected to achieve a traffic volume balance.

The purpose of this study is to minimize the measurement errors and to build an optimization model that satisfies the requirement of traffic volume balance by using TCS (Toll Collection System) traffic volume data in order to correct the expressway traffic volume collected through annual surveys. In addition, the model developed in this study was applied to an actual highway to compare and verify with actual traffic volume. This study is structured as follows. Section 2 reviews previous studies on traffic volume correction methods and traffic volume balance. Section 3 uses TCS traffic volume and measured traffic volume to establish traffic volume balance. Section 4 develops a method to correct the measured traffic volume based on traffic volume balance. Section 5 applies the methodology developed in the previous section to actual expressway routes. Finally, Section 6 presents the conclusions of this study and suggests some directions for future research.

\section{LITERATURE REVIEW}

Numerous studies have been conducted on approaches to correcting measured traffic volume to improve the accuracy of measured expressway traffic volume. Studies on the correction of measured traffic volume can be classified by the approach employed into methods of fundamental consistency, historical consistency, and network consistency. The fundamental consistency correction method corrects the traffic volume error based on traffic flow theory but when this approach is used, it is impossible to correct the measured traffic volume in the event of very small errors [4]. The historical consistency correction method corrects the error based on past historical traffic volume. But there are limits to this method as past historical traffic volume is not always available such as when traffic patterns change due to traffic accidents or new road construction [9]. The network consistency method requires accurate actual traffic volume information from the main line or ramp, but this can be difficult to collect [13]. This study was able to utilize TCS traffic volume data, which is equivalent to the actual traffic volume, and therefore, reviewed previous studies based on the network consistency method.

Shaw and Noyce [12] corrected the measured traffic volume of the main line and ramp to satisfy the requirement of traffic volume balance based on the measured traffic volume collected at each end of a certain road section. The measured traffic volume collected at each end of the road section must be accurate because it serves as the standard for correcting the measured traffic volume of the main line and ramp of the road section. Kwon et al. [11] addressed the problem of balancing the measured traffic volume collected from the main line using the matrix-based weighted least-squares regression model. This model is based on the confidence level of each traffic volume detector. Xin et al. [14] assumed that the measured traffic volume collected from the detector has a certain range of error. An optimization model was used to correct the measured traffic volume from the main line and ramp to satisfy the requirement of traffic volume balance within the error range. Vanajakshi and Rilett [2] verified the traffic volume balance by comparing the existing measured traffic volume from a detector on the expressway main line with the entering measured traffic volume from a detector nearby. When a difference occurs in the comparison, it is considered to be a violation of the traffic volume balance, and a non-linear optimization model is applied to correct the measured traffic volume. Wall and Dailey [15] established a reference detector to verify and correct the measured traffic volume on the expressway main line and set the measured traffic volume collected from this detector as the initial value. The measured traffic volume configured as the initial value was used to verify whether the adjacent measured traffic volume satisfied the traffic volume balance. A correction factor was applied if the traffic 
volume balance was not satisfied. The corrected measured traffic volume was used again to verify and correct the adjacent measured traffic volumes. The FHWA Traffic Monitoring Guide [16] presents a model for adjusting ramp traffic to ensure traffic volume balancing. TMG assumed that the measured traffic volume of the main line is accurate. However, traffic volume imbalance is not only caused by the ramp traffic volume, but also by the measured traffic volume collected from the main line. Zhao et al. [10] corrected the measured traffic volume of the main line and ramp by satisfying the traffic volume balance requirement using the least squares regression model while minimizing the traffic volume difference before and after the correction. The proposed model requires a standard deviation of the measured traffic volume and assumes that the error has a normal distribution. Table 1 summarizes the previous studies that correct the measured traffic volume based on network consistency.

This study differs from the previous studies in the way that it uses TCS traffic volume which is actual traffic volume to minimize the measurement error and satisfy the traffic balance. Previous studies based on network consistency assumed that the measured traffic volume collected from the main line or ramp was the actual traffic volume and developed a methodology to correct the measured traffic volume to satisfy the traffic volume balance.

Table 1: Correction methods of measured traffic volume based on network consistency.

\begin{tabular}{|c|c|c|}
\hline Category & Measured traffic volume & True traffic volume \\
\hline Shaw and Noyce (2014) & $\begin{array}{c}\text { Traffic detector volume } \\
\text { (link and ramp of analysis } \\
\text { road) }\end{array}$ & $\begin{array}{l}\text { Traffic detector volume } \\
\text { (starting and ending link of } \\
\text { analysis road) }\end{array}$ \\
\hline Kwon et al. (2008) & $\begin{array}{l}\text { Traffic detector volume } \\
\text { (link of analysis road) }\end{array}$ & $\begin{array}{l}\text { Traffic detector volume } \\
\text { (link of analysis road) }\end{array}$ \\
\hline Xin et al. (2008) & $\begin{array}{c}\text { Traffic detector volume } \\
\text { (link and ramp of analysis } \\
\text { road) }\end{array}$ & $\begin{array}{c}\text { Traffic detector volume } \\
\text { (link and ramp of analysis } \\
\text { road) }\end{array}$ \\
\hline $\begin{array}{l}\text { Vanajakshi and Rilett } \\
\text { (2004) }\end{array}$ & $\begin{array}{l}\text { Traffic detector volume } \\
\text { (link of analysis ROAD) }\end{array}$ & $\begin{array}{l}\text { Traffic detector volume } \\
\text { (link of analysis road) }\end{array}$ \\
\hline Wall and Dailey (2003) & $\begin{array}{l}\text { Traffic detector volume } \\
\text { (link of analysis road) }\end{array}$ & $\begin{array}{l}\text { Traffic detector volume } \\
\text { (link of analysis road) }\end{array}$ \\
\hline $\begin{array}{c}\text { FHWA Traffic Monitoring } \\
\text { Guide (2001) }\end{array}$ & $\begin{array}{c}\text { Traffic detector volume } \\
\text { (link and ramp of analysis } \\
\text { road) }\end{array}$ & $\begin{array}{l}\text { Traffic detector volume } \\
\text { (link of analysis road) }\end{array}$ \\
\hline Zhao et al. (1998) & $\begin{array}{c}\text { Traffic detector volume } \\
\text { (link and ramp of analysis } \\
\text { road) }\end{array}$ & $\begin{array}{c}\text { Traffic detector volume } \\
\text { (link and ramp of analysis } \\
\text { road) }\end{array}$ \\
\hline This paper & $\begin{array}{l}\text { Traffic detector volume } \\
\text { (link of analysis road) }\end{array}$ & $\begin{array}{l}\text { TCS traffic volume } \\
\text { (ramp of analysis road) }\end{array}$ \\
\hline
\end{tabular}




\section{ESTABLISHING AND MEASURING OF TRAFFIC VOLUME BALANCE}

\subsection{Data collection}

This study used the traffic volume measured on the expressway and the TCS traffic data gathered on the 3rd Thursday of October 2015 as shown in Table 2. The measured traffic volume is gathered according to the direction of the vehicles on the road segment between IC and IC, IC and JC, JC and IC, and JC and JC. TCS traffic volume is the data of vehicles using the expressway tollgate by the mechanical toll collection facilities, which identifies the traffic volume entering and exiting the expressway tollgate.

In this study, the concept of traffic volume balance is established by using the TCS traffic volume and the traffic volume measured on the expressway. Then, it is identified whether the traffic volume measured on the expressway satisfies traffic volume balance. Finally, the correcting methodology is proposed that the traffic volume on the expressway with the traffic volume imbalance satisfies the traffic volume balance.

\subsection{Establishing the concept of traffic volume balance}

The traffic volume measured on the expressway can be classified into 2 types (Type A, Type B) according to the collection location, as shown in Fig. 1. Type A collects the traffic volume measured by direction from the main line section between IC and IC, IC and JC, and JC and IC, which can identify the traffic volume entering and exiting the main line section by using TCS traffic volume entering and exiting the expressway tollgate. Type B collects the traffic volume measured by direction from the main line section between JC and JC, in which it is impossible to identify the traffic volume entering and exiting the main line by TCS traffic volume because there is no tollgate between JC and JC. Therefore, this study established the traffic volume balance for Type A.

Fig. 2 takes a closer look at TYPE A, the target of analysis in this study. Here, the traffic volume balance equation can be established as shown in eqns (1) and (2), based on the concept that the traffic volume measured on the expressway must satisfy the requirement of traffic volume balance in reference to network consistency

$$
\begin{aligned}
& x_{d}^{f}=x_{u}^{f}-T_{\text {in }}^{f}+T_{\text {out }}^{f}, \\
& x_{d}^{r}=x_{u}^{r}-T_{\text {in }}^{r}+T_{\text {out }}^{r} .
\end{aligned}
$$

Here:

$x_{u}^{f}=$ Forward(f) Upstream(u) traffic volume, $x_{d}^{f}=$ Forward(f) Downstream(d) traffic volume; $x_{u}^{r}=$ Reverse(r) Upstream(u) traffic volume, $x_{d}^{r}=$ Reverse(r) Downstream(d) traffic volume;

$T_{i n}^{f}=$ Forward(f) tollgate entering traffic, $T_{\text {out }}^{f}=$ Forward(f) tollgate existing traffic;

$T_{i n}^{r}=$ Reverse(r) tollgate entering traffic, $T_{\text {out }}^{r}=$ Reverse(r) tollgate existing traffic.

Table 2: Data collection outline.

\begin{tabular}{|c|c|c|}
\hline Category & TCS traffic volume & Traffic volume of expressway \\
\hline $\begin{array}{c}\text { Date of } \\
\text { collection }\end{array}$ & $\begin{array}{c}\text { 3rd Thursday of October 2015 } \\
(24 \text { hour })\end{array}$ & $\begin{array}{c}\text { 3rd Thursday of October 2015 } \\
(24 \text { hour) }\end{array}$ \\
\hline $\begin{array}{c}\text { Target of } \\
\text { collection }\end{array}$ & $\begin{array}{c}\text { Traffic volume between } \\
\text { expressway business tollgate }\end{array}$ & $\begin{array}{c}\text { Traffic volume of links between } \\
\text { IC-IC, IC-JC, JC-IC, and JC-JC }\end{array}$ \\
\hline Vehicle type & 5 types & 12 types \\
\hline
\end{tabular}




\section{TYPE A}

TYPE B

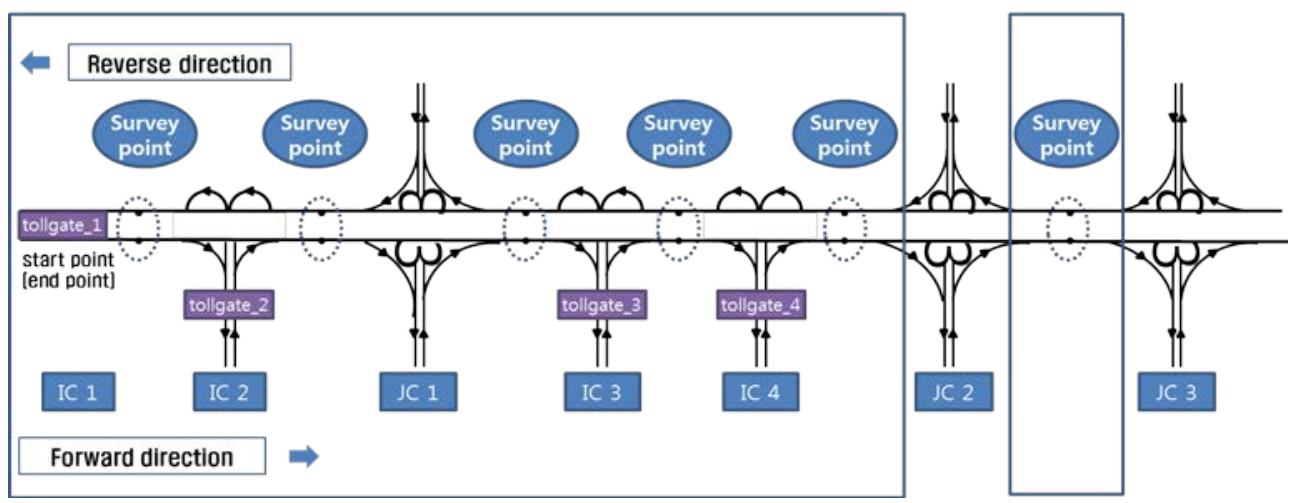

Figure 1: Collection types of measured traffic volume on expressway.

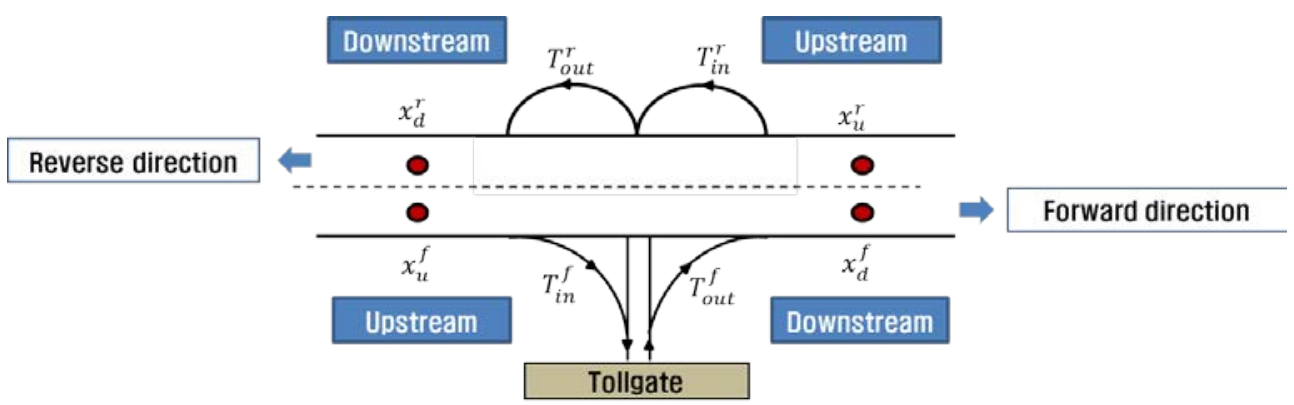

Figure 2: Traffic volume of expressway link and ramp by direction and point.

The TCS traffic volume cannot grasp the entering traffic volume $\left(T_{i n}^{f}, T_{i n}^{r}\right)$ and exiting traffic volume $\left(T_{\text {out }}^{f}, T_{\text {out }}^{r}\right)$ by direction from the tollgate. Therefore, eqns (1) and (2) can be organized and expressed simultaneously as eqn (3). Eqn (3) means that the difference between the TCS traffic volume entering and exiting the tollgate is equal to the sum of traffic volume differences by direction of the main line located on the left and right sides of the tollgate. The left-hand side $T_{i n}^{f}+T_{i n}^{r}$ is the TCS traffic volume entering the tollgate, and $T_{\text {out }}^{f}+T_{\text {out }}^{r}$ is the TCS traffic volume exiting the tollgate. The right-hand side $x_{u}^{f}-x_{d}^{r}$ is the traffic volume difference by direction of the main line located on the left side of the tollgate, and $x_{u}^{r}-x_{d}^{f}$ is the traffic volume difference by direction of the main line located on the right side of the tollgate. Here, it is defined that the smaller the difference between $\left(T_{i n}^{f}+T_{i n}^{r}\right)-$ $\left(T_{\text {out }}^{f}+T_{\text {out }}^{r}\right)$ using the TCS traffic volume and $\left(x_{u}^{f}-x_{d}^{r}\right)+\left(x_{u}^{r}-x_{d}^{f}\right)$ based on the measured expressway traffic volume, the more it satisfies the requirement of traffic volume balance

$$
\left(T_{\text {in }}^{f}+T_{\text {in }}^{r}\right)-\left(T_{\text {out }}^{f}+T_{\text {out }}^{r}\right)=\left(x_{u}^{f}-x_{d}^{r}\right)+\left(x_{u}^{r}-x_{d}^{f}\right)
$$




\subsection{Measuring traffic volume balance}

The traffic volume balance was measured in terms of the total traffic volume because of the different types of vehicles between TCS traffic volume and the traffic volume measured on the expressway. Table 3 shows the results of measuring traffic volume balance for 21 sections of the Gyeongbu Expressway. Overall, there was a traffic volume imbalance across all of the sections. Thus, it is necessary to correct the traffic volume measured on the expressway which shows a traffic imbalance to satisfy the requirement of traffic volume balance.

Table 3: Results of estimation of traffic volume balancing on Gyeongbu Expressway.

\begin{tabular}{|c|c|c|c|c|}
\hline \multicolumn{2}{|r|}{ Category } & $\left(x_{u}^{f}-x_{d}^{r}\right)+\left(x_{u}^{r}-x_{d}^{f}\right)$ & $\left(T_{\text {in }}^{f}+T_{\text {in }}^{r}\right)-\left(T_{\text {out }}^{f}+T_{\text {out }}^{r}\right)$ & $\begin{array}{l}\text { Difference } \\
\text { (1)-(2) }\end{array}$ \\
\hline \multirow[b]{2}{*}{ Geoncheon } & Gyeongju IC $\sim$ Geoncheon IC & \multirow[b]{2}{*}{-373} & \multirow[b]{2}{*}{537} & \multirow[b]{2}{*}{-910} \\
\hline & $\begin{array}{c}\text { Geoncheon IC } \sim \text { Yeongcheon } \\
\text { IC }\end{array}$ & & & \\
\hline \multirow{2}{*}{ Yeongcheon } & $\begin{array}{c}\text { Geoncheon IC } \sim \text { Yeongcheon } \\
\text { IC }\end{array}$ & \multirow{2}{*}{$-6,753$} & \multirow{2}{*}{-15} & \multirow{2}{*}{$-6,738$} \\
\hline & $\begin{array}{c}\text { Yeongcheon IC } \sim \text { Gyeongsan } \\
\text { IC }\end{array}$ & & & \\
\hline \multirow{2}{*}{ Gyeongsan } & $\begin{array}{c}\text { Yeongcheon IC } \sim \text { Gyeongsan } \\
\text { IC }\end{array}$ & \multirow{2}{*}{4,543} & \multirow{2}{*}{96} & \multirow{2}{*}{4,447} \\
\hline & $\begin{array}{c}\text { Gyeongsan IC } \sim \text { Dongdaegu } \\
\text { JCT }\end{array}$ & & & \\
\hline \multirow{2}{*}{ Namgumi } & Waegwan IC $\sim$ Namgumi IC & \multirow{2}{*}{-623} & \multirow{2}{*}{592} & \multirow{2}{*}{$-1,215$} \\
\hline & Namgumi IC $\sim$ Gumi IC & & & \\
\hline \multirow{2}{*}{ Gumi } & Namgumi IC $\sim$ Gumi IC & \multirow{2}{*}{551} & \multirow{2}{*}{96} & \multirow{2}{*}{455} \\
\hline & Gumi IC $\sim$ Gimcheon JCT & & & \\
\hline \multirow{2}{*}{ Daejeon } & Biryong JCT $\sim$ Daejeon IC & \multirow{2}{*}{1,567} & \multirow{2}{*}{-600} & \multirow{2}{*}{2,167} \\
\hline & Daejeon IC $\sim$ Hoedeok JCT & & & \\
\hline \multirow{2}{*}{ Sintanjin } & Hoedeok JCT $\sim$ Sintanjin IC & \multirow{2}{*}{462} & \multirow{2}{*}{-157} & \multirow{2}{*}{619} \\
\hline & Sintanjin IC $\sim$ Cheongwon IC & & & \\
\hline \multirow{2}{*}{ Namcheongju } & Sintanjin IC $\sim$ Cheongwon IC & \multirow{2}{*}{$-1,626$} & \multirow{2}{*}{-133} & 1403 \\
\hline & Cheongwon IC $\sim$ Nami JCT & & & $-1,493$ \\
\hline Cheonoiu & Nami JCT $\sim$ Cheongju IC & 404 & $1148+2$ & 5742 \\
\hline (2) & Cheongju IC $\sim$ Mokchon IC & & & , \\
\hline Mokchon & Cheongju IC $\sim$ Mokchon IC & 2330 & 1400 & 030 \\
\hline IVIOKCEIIII & Mokchon IC $\sim$ Cheonan JCT & 2,539 & 1,400 & 939 \\
\hline Cheonan & Mokchon IC $\sim$ Cheonan JCT & 4147 & 5060 & 1812 \\
\hline 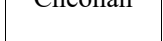 & Cheonan JCT $\sim$ Cheonan IC & $-4,14 /$ & $-5,700$ & 1,010 \\
\hline Bukcheonan & Cheonan IC $\sim$ Bukcheonan IC & 5085 & 535 & 4550 \\
\hline 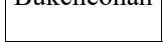 & Bukcheonan IC $\sim$ Anseong IC & , & 年 & ס סרנד \\
\hline Anseong & Bukcheonan IC $\sim$ Anseong IC & 2648 & 1420 & 1228 \\
\hline Hinsovitg & Anseong IC $\sim$ Anseong JCT & 2, & $1,+20$ & 1,220 \\
\hline Giheu & Dongtan JCT $\sim$ Giheung IC & 8 & 1 & 17100 \\
\hline Gintung & Giheung IC $\sim$ Suwon IC & $-10,0$ & 1,221 & -11, \\
\hline
\end{tabular}




\section{MODEL DEVELOPMENT AND VERIFICATION}

\subsection{Model development}

The traffic volume measured on the expressway based on the annual traffic volume report includes measurement errors, as shown in eqn (4). There is always a measurement error because the exact amount of actual traffic cannot be identified. This results in a traffic volume imbalance in terms of network consistency

$$
\mathrm{y}_{i}^{j}=x_{i}^{j}+e_{i}^{j} .
$$

Here, $\mathrm{y}_{i}^{j}=$ actual traffic volume $(\fallingdotseq$ corrected traffic volume $)$,

$x_{i}^{j}=$ traffic volume measured on the expressway,

$e_{i}^{j}=$ measurement error,

$\mathrm{i}=$ upstream or downstream, $\mathrm{j}=$ forward or reverse.

This study used the optimization model as shown in eqn (5) to both minimize the measurement error and correct the traffic volume imbalance. The objective function of the optimization model calculates the corrected traffic volume that minimizes the measurement error. The first constraint condition is that it satisfies the requirement of traffic volume balance. Using eqn (3), the sum of the difference in traffic volume by direction of the main line located on the left and right sides of the tollgate corrects the measured traffic volume equal to the difference between the entering and exiting TCS traffic volume of the tollgate. Second, when the measured traffic volume is corrected to the traffic volume that satisfies the requirement of traffic volume balance, it is corrected by the difference in traffic volume imbalance, as it can be corrected to an extreme. Third, an upper limit value or a lower limit value is set for $y_{u}^{f}+y_{u}^{r}$ and $y_{d}^{f}+y_{d}^{r}$, when the measured traffic volume is corrected by the imbalance difference. The difference between the entering and exiting TCS traffic volume of the tollgate that is, when $\left(T_{\text {in }}^{f}+T_{\text {in }}^{r}\right)-\left(T_{\text {out }}^{f}+T_{\text {out }}^{r}\right) \geq 0$ should be $y_{u}^{f}+y_{u}^{r} \geq y_{d}^{f}+y_{d}^{r}$ because $\left(y_{u}^{f}-y_{d}^{r}\right)+\left(y_{u}^{r}-y_{d}^{f}\right) \geq 0$. On the contrary, when $\left(T_{\text {in }}^{f}+T_{\text {in }}^{r}\right)-\left(T_{\text {out }}^{f}+T_{\text {out }}^{r}\right) \leq$ 0 , it should be $y_{u}^{f}+y_{u}^{r} \leq y_{d}^{f}+y_{d}^{r}$.

$$
\text { Minimize } \sum\left[y_{i}^{j}-x_{i}^{j}\right], \mathrm{i}=\mathrm{u} \text { or } \mathrm{d}, \mathrm{j}=\mathrm{f} \text { or } \mathrm{r}
$$

s.t.

Conservation : $\left(T_{i n}^{f}+T_{\text {in }}^{r}\right)-\left(T_{\text {out }}^{f}+T_{\text {out }}^{r}\right)=y_{u}^{f}-y_{d}^{r}+y_{u}^{r}-y_{d}^{f}$.

Correction total amount: $\left(T_{i n}^{f}+T_{i n}^{r}\right)-\left(T_{\text {out }}^{f}+T_{\text {out }}^{r}\right)-\left(x_{u}^{f}-x_{d}^{r}+x_{u}^{r}-x_{d}^{f}\right)=$

$$
\left(y_{u}^{f}-x_{u}^{f}\right)+\left(y_{d}^{r}-x_{d}^{r}\right)+\left(y_{u}^{r}-x_{u}^{r}\right)+\left(y_{d}^{f}-x_{d}^{f}\right) .
$$

Correction range : $\left(y_{u}^{f}+y_{u}^{r}\right) \geq\left(y_{d}^{f}+y_{d}^{r}\right)$ if, $\left(T_{\text {in }}^{f}+T_{\text {in }}^{r}\right)-\left(T_{\text {out }}^{f}+T_{\text {out }}^{r}\right) \geq 0$.

$$
\left(y_{u}^{f}+y_{u}^{r}\right) \leq\left(y_{d}^{f}+y_{d}^{r}\right) \text { if, }\left(T_{\text {in }}^{f}+T_{\text {in }}^{r}\right)-\left(T_{\text {out }}^{f}+T_{\text {out }}^{r}\right) \leq 0 .
$$

Non-negative : $y_{u}^{f}, y_{d}^{r}, y_{u}^{r}, y_{d}^{f} \geq 0$.

Here

$y_{u}^{f}=$ forward(f) upstream(u) corrected traffic, $y_{d}^{r}=$ reverse(r) downstream(d) corrected traffic, $y_{d}^{f}=$ forward(f) downstream(d) corrected traffic, $y_{u}^{r}=$ reverse(r) upstream(u) corrected traffic, $\mathrm{f}=$ forward, $\mathrm{r}=$ reverse, $\mathrm{u}=$ upstream, $\mathrm{d}=$ downstream. 


\subsection{Model verification}

In this study, the model was verified from 12 main lines near the start or end point of the expressway route where the actual traffic volume of TCS data can be identified. For example, as shown in Fig. 1, the actual traffic volume $y_{u}^{f}$ at the starting point is the same as the TCS traffic volume exiting from tollgate 1 . According to eqn (1), the actual traffic volume $y_{d}^{f}$ can be calculated by subtracting the entering traffic volume $T_{i n}^{f}$ from the actual traffic volume $y_{u}^{f}$, then adding the existing traffic volume $y_{u}^{f}$. Here, the entering traffic volume $T_{i n}^{f}$ is the TCS traffic volume entering tollgate 2 from tollgate 1 , and the exiting traffic volume $T_{\text {out }}^{f}$ is the total TCS traffic volume exiting tollgate 2 excluding the traffic volume flowing out to tollgate 1 . The actual traffic volumes $y_{u}^{r}$ and $y_{d}^{r}$ can be calculated in the same way. As a result of verifying the model, as shown in Table 4 , the corrected traffic volume showed a smaller difference from the actual traffic volume compared to the measured traffic volume before correction. This means that the measurement error is reduced when the measured traffic volume showing a traffic volume imbalance is corrected to satisfy the requirement of traffic volume balance.

Table 4: Results of model verification.

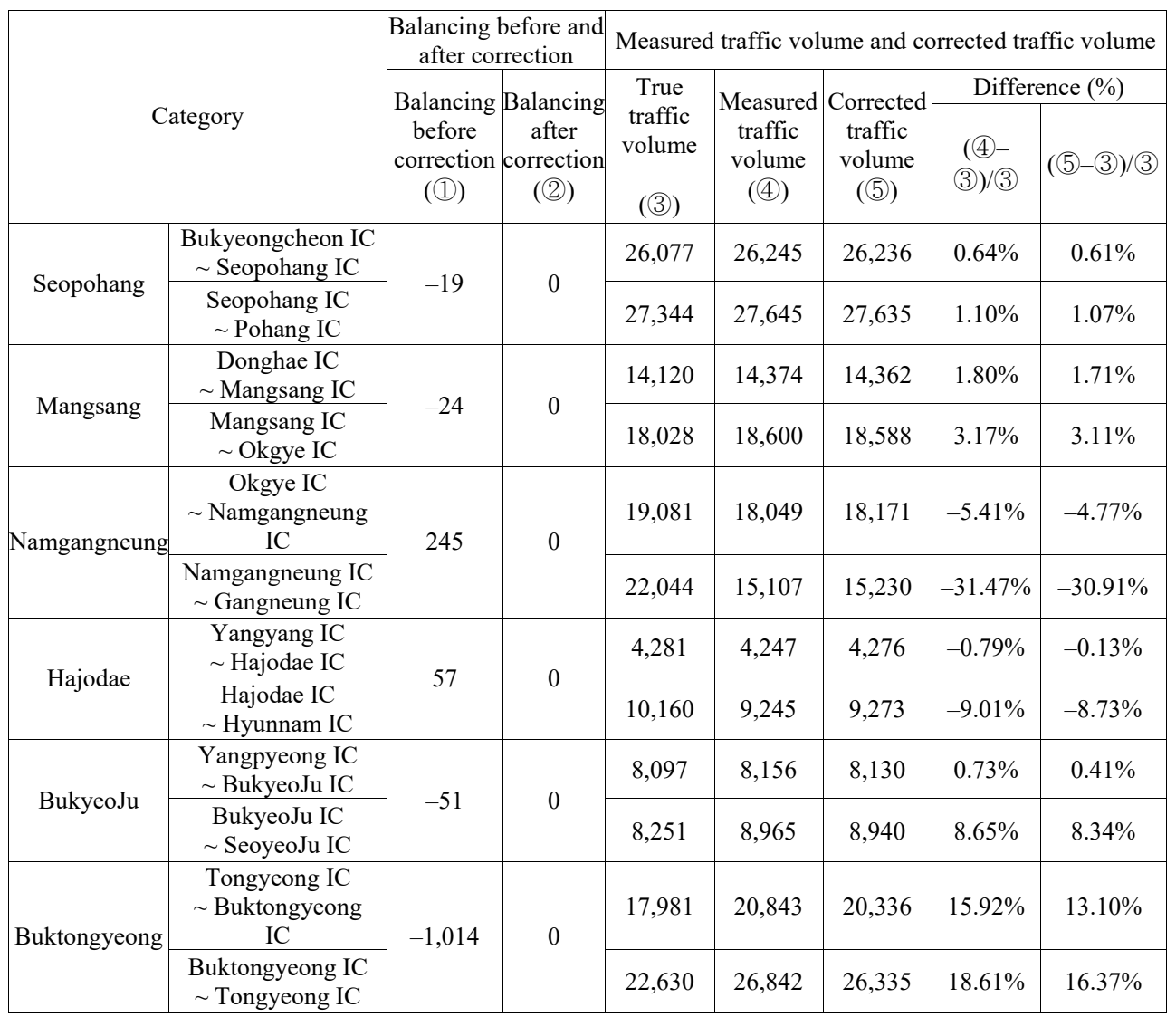


Table 5: Results of measured traffic volume correction on Gyeongbu Expressway.

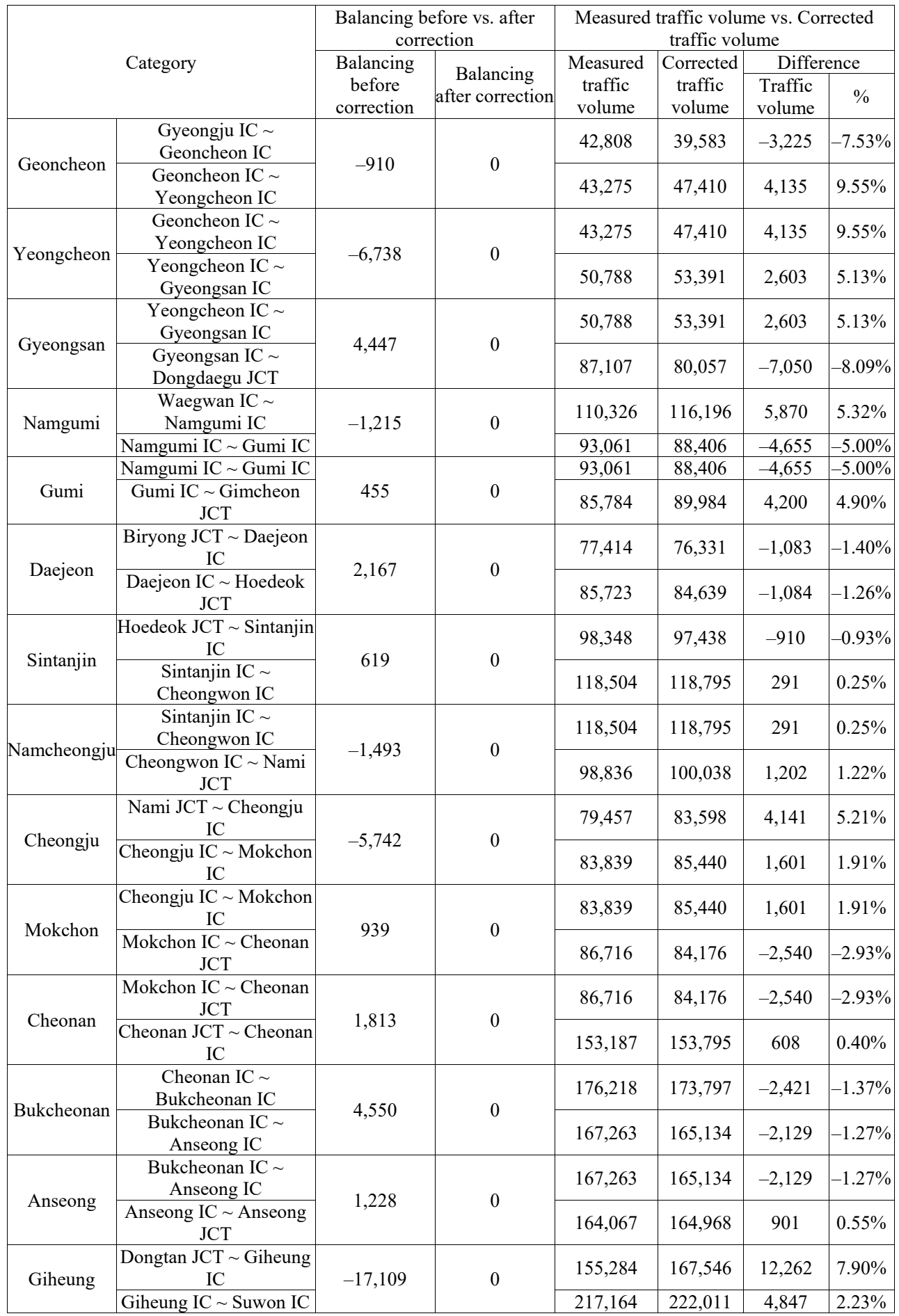




\section{MODEL APPLICATION AND RESULT ANALYSIS}

As shown in Table 5, the model of this study was applied to 21 sections of the Gyeongbu Expressway that show a traffic volume imbalance. As a result of applying the model, the measured traffic volume of 21 sections of the Gyeongbu Expressway was corrected by $8.09 \% \sim 9.55 \%$, and the measurement error was decreased by as much as the corrected traffic volume. In other words, the corrected traffic volume of all sections satisfies the requirement of traffic volume balance, resulting in reduced measurement errors for the corrected traffic volume compared to the measured traffic volume. In particular, the section between Giheung tollgate (Dongtan JCT $\sim$ Giheung IC, Giheung IC $\sim$ Suwon IC) is the section where the measured traffic was most corrected with a total of 17,109 vehicles corrected, showing the largest improvement in traffic volume imbalance.

\section{CONCLUSION AND FUTURE RESEARCH}

This study developed an optimization model that minimizes measurement errors while satisfying the TCS traffic volume and the traffic volume balance in order to correct the measured traffic volume. When the optimization model was applied to traffic volume measured on the expressway, it was found that the corrected traffic volume showed a smaller difference from the actual traffic volume compared to the measured traffic volume before correction. As a result, the measurement error was reduced, when the measured traffic volume showing a traffic volume imbalance was corrected to satisfy the traffic volume balance. Through applying the model to 21 sections of the Gyeongbu Expressway showing a traffic volume imbalance, it was found that the measured traffic volume of 21 sections of the Gyeongbu Expressway was corrected by $-8.09 \% \sim 9.55 \%$, and the measurement error decreased by the amount of the corrected traffic volume.

While this study is significant in that it improved the accuracy of measuring traffic volume on the expressway, which is critical as the importance of expressways increase, many improvements are required. First, this study limits the spatial range of the measured traffic volume gathered between IC and IC, IC and JC, and JC and IC. In other words, the measured traffic volume collected from the section with no tollgate between the $\mathrm{JC}$ and $\mathrm{JC}$ was not corrected. In the future, it is necessary to correct the traffic volume measured on the expressway considering these limitations. Second, while this study analyzed the traffic volume in terms of total traffic volume without classifying the vehicle type, there should be an analysis that classifies the vehicle type, such as cars and buses. Third, this study applied the model to the Gyeongbu Expressway, but it should also be applied to other expressway routes.

\section{REFERENCES}

[1] Ministry of Land, Infrastructure and Transport, Annual traffic volume report, pp. 5, 2016.

[2] Vanajakshi, L. \& Rilett, L., Loop detector data diagnostics based on conservation-ofvehicles principle. Transportation Research Record: Journal of the Transportation Research Board, 1870, pp. 162-169, 2004. DOI: 10.3141/1870-21.

[3] Lee, H.P., NamKoong, S., Kim, S.H. \& Kim, J., Improvement of a preprocessing of archived traffic data collected by expressway vehicle detection system. Journal of the Korea Institute of Intelligent Transport Systems, 12(1), pp. 15-27, 2013. DOI: $10.12815 /$ kits.2013.12.1.015.

[4] Jagadeesh, G.R., Dhinesh, G.R. \& Srikanthan, T., Method for accuracy assessment of aggregated freeway traffic data. IET Intelligent Transport Systems, 8(4), pp. 407-414, 2013. DOI: 10.1049 /iet-its.2013.0094. 
[5] Hu, P.S., Proof of concept of ITS as an alternative data resource: A demonstration project of Florida and New York data, ORNL Oak Ridge National Laboratory (US), pp. 33, 2001.

[6] Chen, C., Kwon, J., Rice, J., Skabardonis, A. \& Varaiya, P., Detecting errors and imputing missing data for single-loop surveillance systems. Transportation Research Record. Journal of the Transportation Research Board, 1855, pp. 160-167, 2003.

[7] Zheng, P. \& Mike, M., An investigation on the manual traffic count accuracy. Procedia-Social and Behavioral Sciences 43, pp. 226-231, 2012. DOI: 10.1016/j.sbspro.2012.04.095.

[8] Turner, S.M., Eisele, W.L., Gajewski, B.J., Albert, L.P. \& Benz, R.J., ITS Data Archiving: Case Study Analysis of San Antonio TransGuide Data, pp. 90-113, 1999.

[9] De Oña, J., Gómez, P. \& Mérida-Casermeiro, E., Method to detect malfunctioning traffic count stations. IET Intelligent Transport Systems, 6(4), pp. 364-371, 2012. DOI: 10.1049 /iet-its.2011.0102.

[10] Zhao, M., Garrick, N. \& Achenie, L., Data Reconciliation-Based Traffic Count Analysis System. Transportation Research Record: Journal of the Transportation Research Board, 1625, pp. 12-17, 1998. DOI: 10.3141/1625-02.

[11] Kwon, J., Petty, K., Shieh, E., Kopelias, P. \& Papandreou, K., Automatic Method for Imputing and Balancing Link Traffic Counts, TRB 87rd Annual Meeting, No. 082322, pp. 1-7, 2008.

[12] Shaw, J.W. \& Noyce, D.A., Automated Optimal Balancing of Traffic Volume Data for Large Access-Controlled Highway Networks and Freeway-to-Freeway Interchanges, TRB 93rd Annual Meeting, No. 14-3565, pp. 1-13, 2014.

[13] Kikuchi, S. \& Miljkovic, D., Method to preprocess measured traffic data for consistency: Application of fuzzy optimization concept. Transportation Research Record: Journal of the Transportation Research Board, 1679, pp. 73-80, 1999. DOI: $10.3141 / 1679-10$.

[14] Xin, W., Hourdos, J. \& Michalopoulos, P., Streamlining of the Traffic Modeling Process for Implementation in the Twin Cities Freeway Network-Phase II. No. MN/RC-2006-14, pp. 15-18, 2006.

[15] Wall, Z.R. \& Dailey, D.J., Algorithm for detecting and correcting errors in archived traffic data. Transportation Research Record: Journal of the Transportation Research Board, 1855, pp. 183-190, 2003. DOI: 10.3141/1855-23.

[16] US Department of Transportation, Fhwa, Traffic Monitoring Guide, pp. 3-41, 2001. 